\title{
Discriminative value of cardiopulmonary progressive exercise test in mitochondrial myopathy and chronic fatigue syndrome
}

\author{
Miriam Estébanez Muñoz ${ }^{1 *}$,Francisco García ${ }^{2}$, Francisco Javier Arpa Gutiérrez ${ }^{3}$, Patricia Martinez ${ }^{3}$, Jorge F. Gómez \\ Cerezo $^{4}$, Alberto M. Borobia Pérez ${ }^{5}$, Blas Rojo Moreno-Arrones ${ }^{6}$, Franciso J. Barbado Hernández ${ }^{1}$ \\ ${ }^{1}$ Servicio de Medicina Interna, Hospital Universitario La Paz, Madrid, España. \\ ${ }^{2}$ Servicio de Neumología, Hospital Universitario La Paz, Madrid, España. \\ ${ }^{3}$ Servicio de Neurología, Hospital Universitario La Paz, Madrid, España. \\ ${ }^{4}$ Departamento de Medicina Interna, Hospital Infanta Sofía, San Sebastián de los Reyes, Madrid, España. \\ ${ }^{5}$ Servicio de Farmacología Clínica, Hospital Universitario La Paz, Facultad de Medicina. Universidad Autónoma de Madrid, Madrid España. \\ ${ }^{6}$ Sección de Neumología. Departamento de Medicina. Hospital Infanta Sofía, San Sebastián de los Reyes, Madrid, España. \\ *Author for correspondence: Miriam Estébanez Muñoz (mirestmun@gmail.com)
}

\section{ABSTRACT}

OBJECTIVE: To determine the diagnostic accuracy of the cardiopulmonary exercise testing to discriminate between mitochondrial myopathy (MM) and chronic fatigue syndrome (CFS).

METHODS: Nineteen CFS and 27 MM patients (18-65 years) were consecutively recruited from subjects sent to a neurology consultation by exercise intolerance. 18 healthy subjects were recruited as control group. A baseline spirometry and a symptom-limited incremental cycle exercise test were conducted in all subjects. Cardiovascular response was mainly assessed by the peak heart rate (HR) and the HR slope. Biomechanical efficiency was assessed by the total work oxygen cost $\left(\Delta \mathrm{V}^{\prime} \mathrm{O} 2 / \Delta \mathrm{W}\right)$ during exercise and recovery.

RESULTS: Patients with MM or CFS showed a limited exercise tolerance, demonstrated by a lower peak oxygen uptake and peak work rate than control subjects. CFS patients had a higher HR slope $(9.6 \pm 3.1 \mathrm{vs} .7 .2 \pm 2.11 / \mathrm{ml} / \mathrm{Kg}, \mathrm{p}=0.02)$ and a lower work $\Delta \mathrm{V}^{\prime} \mathrm{O} 2 / \Delta \mathrm{W}(12.1 \pm 2.9 \mathrm{vs} .16 .0 \pm 3.9 \mathrm{ml} / \mathrm{min} / \mathrm{w}, \mathrm{p}<0.001)$ than $\mathrm{MM}$ patients. The area under the ROC curves of the HR slope and work $\Delta \mathrm{V}^{\prime} \mathrm{O} 2 / \Delta \mathrm{W}$ to discriminate between CFS and MM were 0.72 (CI95\%:0.56-0.87) and 0.79 (CI95\%:0.65-0.92), respectively.

CONCLUSION: As response parameters to cardiopulmonary exercise testing, HR slope and work $\Delta \mathrm{V}^{\prime} \mathrm{O} 2 / \Delta \mathrm{W}$ have shown to be useful in discriminating between CFS and MM.

Keywords: Chronic fatigue syndrome, mitochondrial myopathy, cardiopulmonary exercise testing.

Received May23, 2016; Accepted May 28, 2016; Published June 02, 2016.

Copyright: (C 2016 Authors. This is an open-access article distributed under the terms of the Creative Commons Attribution License, which permits unrestricted use, distribution, and reproduction in any medium, provided the original author and source are credited. Editor: Antonio J. Carcas Sansuán

Cite as: Estébanez M., García F., Arpa FJ., Martínez P., Gómez JF., Borobia AM, Moreno-Arrones BR, Barbado FJ. Discriminative value of cardiopulmonary progressive exercise test in mitochondrial myopathy and chronic fatigue syndrome. IBJ Plus 2016 1(1):e0002. Funding: The author(s) declared that no grants were involved in supporting this work.

Competing Interests: Miriam Estébanez Muñoz is the executive editor of IBJ Infectious Diseases. Alberto M. Borobia Pérez is the executive editor of IBJ Clinical Pharmacology. 


\section{I ntroduction}

Chronic fatigue syndrome (CFS) and mitochondrial myopathy (MM) can present as exercise intolerance in adults with a normal creatine phosphokinase (CK) and electromyography. CSF is an illness of unknown cause, characterized by disabling fatigue lasting more than 6 months, and prominently features subjective impairments in concentration, short-term memory and sleep as well as musculoskeletal pain, in absence of a recognizable medical and psychiatric disorder (1). MM is one of the most common muscle diseases (2). Primary mitochondrial respiratory chain disease is a heterogeneous group of disorders characterized by impaired energy metabolism due to presumed genetically-based oxidative phosphorylation dysfunction. Some patients present with symptoms that are strongly suggestive of a mitochondrial cytopathy, but many have nonspecific symptoms that overlap with other diagnosis as CFS. It is probably that true cases of MM had been diagnosed as CFS. So, it is necessary to be in mind these disorders before the final diagnosis of CFS. However, the study of the oxidative phosphorylation requires an extensive laboratory testing, including a muscle biopsy (3). It would be interesting in the clinical practice to have a noninvasive and easy-to-conduct test, to discriminate between both pathologies.

The exercise tolerance test has been studied as a diagnostic tool to compare CFS patients with controls (4-7), as well as to compare MM patients with controls (8-14). Most studies on the physical work capacity of CFS have assessed the aerobic capacity by ensuring maximal oxygen consumption (V'O2 max) and/or heart rate response during exercise (15-19). A typical finding in these studies is a low or near normal V'O2max $(18,19)$ and lower than anticipated maximal heart rate $(17,19-22)$. Thus, the picture emerging from previous findings is that CFS patients have an aerobic capacity lower than expected when compared with agematched healthy subjects and an elevated subjective perception of exercise intensity (19). Recent evidence suggests that cardiovascular dysregulation may play an important role in the etiology of this syndrome $(17,23$ 25).

The few published reports of pulmonary function and exercise performance in patients with mitochondrial disease have found abnormal cardiac and ventilatory responses, low maximal oxygen uptake, high respiratory exchange ratio at maximal exercise, and elevated blood lactate levels during exercise that recovers slowly following completion of exercise $(26,27)$. The low oxygen cost of exercise (oxygen uptake/Watt) reported in MM patients (27) has been interpreted as an increase in exercise efficiency. Nevertheless, since it has been described in other entities (28), the patients with MM might develop an oxygen deficit during the exercise that is repaid as an oxygen debt during the recovery after the exercise. Thus, to obtain an accurate measure the biomechanical efficiency of these patients, the total oxygen cost (work $\left.\Delta \mathrm{V}^{\prime} \mathrm{O} 2 / \Delta \mathrm{W}\right)$ during exercise and recovery must be measured.

As the cardiovascular and metabolic responses to exercise are likely to be different between both pathologies, the aim of this study was to determine the diagnostic accuracy of the cardiopulmonary exercise testing to discriminate between mitochondrial myopathy and chronic fatigue syndrome.

\section{Patients and Methods}

Study subjects

CFS and MM patients, between 18 and 65 years old, were consecutively recruited from subjects sent to a neurology consultation by exercise intolerance during the period 2003-2007.

CSF patients were diagnosed using the Fukuda et al (1) criteria. They presented a normal muscle biopsy, electromyography and a baseline lactate-pyruvate ratio to rule out a mitochondrial dysfunction. MM patients were diagnosed based on muscle biopsy results detecting a significant enzymatic deficiency or on molecular investigation demonstrating a mitochondrial DNA mutation, according to the criteria defined by Walker et al (29). Genetic and biochemical characteristics of patients with MM appear in table 1 . Echocardiographic findings of mitochondrial cardiomyopathy and alterations of the cardiac conduction system (except Left Bundle Branch Block) were considered exclusion criteria, as well as the treatment with B-blockers, calcium-antagonist, diuretics, steroids, acetylsalicylic acid and oral contraceptive.

Control subjects were healthy volunteers randomly selected from the general population of Madrid metropolitan area. All had normal findings on physical examination, spirometry, thoracic radiography, hemogram, electrocardiogram, and biochemistry. This group was recruited to confirm that patients with CFS or $\mathrm{MM}$ presented intolerance exercise during a cardiopulmonary exercise testing.

All participants gave their written consent and the study was approved by the local Ethics Committee for Clinical Investigation.

\section{Procedures}

Spirometry was performed by means of a pneumotachograph (MasterLab Body, Erich Jaeger $\mathrm{GmbH}$, Würzburg, Germany), according to current recommendations (30). Predicted values used were those of the European Coal and Steel Community (31).

After $30 \mathrm{~min}$ of rest, symptom-limited incremental 
cycle exercise tests were conducted on an electronically braked cycle ergometer (Ergobex, Bexen, Spain) according to the standards of the American Thoracic Society/American College of Chest Physicians (ATS/ACCP) statement (32). The exercise test was performed at stable room temperature (20$25^{\circ} \mathrm{C}$ ) and at humidity of $40-60 \%$. Equipment was calibrated immediately before each test.

The initial 2 min consisted of resting data collection followed by $1 \mathrm{~min}$ of unloaded cycling. Subsequently, workload was increased by $15-20 \mathrm{~W} / \mathrm{min}$ until maximal symptom-limited exercise was achieved. Pedaling rates were maintained between 50 and 60 revolutions per minute. At the completion of exercise, subjects were allowed to pedal slowly (20 to 30 revolutions per minute) for the first $60 \mathrm{~s}$ of recovery but then sat quietly on the ergometer. V'O2 measurements were continued after the completion of exercise until the respiratory exchange ratio was $<1.0$ for $30 \mathrm{~s}$ for the determination of oxygen debt (28).

Table 1. Genetic and biochemical characteristics of the patients with mitochondrial myopathy

\begin{tabular}{|c|c|c|c|c|}
\hline & Molecular biology & Biochemical deficiency & COX-negative fibers ${ }^{*}$ & Ragged- red fibers \\
\hline CPEO 1 & No mut./No del. & I & ND & No \\
\hline СРEO2 & ND & ND & ND & $>2 \%$ \\
\hline CPEO 3 & Simple deletion & I+ III+IV & ND & $>2 \%$ \\
\hline CPEO 4 & ND & None & ND & $>2 \%$ \\
\hline CPEO 5 & No mut./No del. & I & ND & No \\
\hline CPEO 6 & No mut./No del. & III & No & No \\
\hline CPEO 7 & Simple deletion & ND & Yes & $>2 \%$ \\
\hline CPEO 8 & No mut./No del. & None & ND & $>2 \%$ \\
\hline CPEO 9 & ND & None & ND & $>2 \%$ \\
\hline CPEO10 & No mut./No del. & None & ND & $>2 \%$ \\
\hline CPEO11 & No mut./No del. & None & ND & $>2 \%$ \\
\hline KSS1 & Multiple deletion & $\mathrm{I}+\mathrm{IV}$ & Yes & $>2 \%$ \\
\hline M1 & No mut./No del. & I & ND & No \\
\hline M2 & 3250tRNAleu & I & Yes & $>2 \%$ \\
\hline M3 & No mut./No del. & $\mathrm{I}+\mathrm{IV}$ & ND & $>2 \%$ \\
\hline M4 & Multiple deletion & None & ND & $>2 \%$ \\
\hline M5 & No mut./No del. & II & ND & No \\
\hline M6 & Multiple deletion & I & ND & $>2 \%$ \\
\hline M7 & No mut./No del. & I & ND & $>2 \%$ \\
\hline M8 & No mut./No del. & I & ND & No \\
\hline MELAS1 & A3243GtRNA ${ }^{\text {leu }}$ & I & ND & $>2 \%$ \\
\hline MELAS2 & A3243GtRNA ${ }^{\text {leu }}$ & I & No & $>2 \%$ \\
\hline MELAS3 & A3243GtRNA ${ }^{\text {leu }}$ & I & Yes & $>2 \%$ \\
\hline MERFF1 & A8344GtRNA ${ }^{\text {lys }}$ & $\mathrm{I}+\mathrm{IV}$ & Yes & $>2 \%$ \\
\hline MERFF2 & A8344GtRNA ${ }^{\text {lys }}$ & ND & ND & ND \\
\hline MERFF3 & A8344GtRNA ${ }^{\text {lys }}$ & ND & ND & ND \\
\hline MERFF4 & A8344GtRNA ${ }^{\text {lys }}$ & ND & ND & ND \\
\hline
\end{tabular}

Abbreviations: $\mathbf{C O X}=$ cytochromeoxidase; SDH=succinic dehydrogenase; $\mathbf{C P E O}=$ chronic progressive external ophtalmoplegia; $\mathbf{E}=$ encephalopathy; $\mathbf{M}=$ miopathy without oftalmoplegia; $\mathbf{K S S}=$ Kearns Sayre síndrome; MELAS=mitochondrial encephalopathy with lactic acidosis and stroke episodes; MERFF=myoclonic encephalopathy with ragged-red fibers; ND=No done; No mut./No del=no mutation/no deletion.

$*$ It was considered positive as $>2 \% \mathrm{COX}$ - negative fibers if $<50$ years of age or $>5 \%$ COX- negative fibers if $>50$ years of age 
Expired gases and ventilation were measured on a metabolic cart that uses a pneumotachograph positioned at the mouth with $\mathrm{O} 2$ and $\mathrm{CO} 2$ analyzers (Oxycon Alpha, Jaeger). This allowed for breath-bybreath measurements of oxygen uptake (V'O2), carbon dioxide production (V'CO2), minute ventilation (VE), respiratory rate (f), and tidal volume (VT). The continuous output of the automated system was recorded and displayed on an on-line PC computer where all data were saved for later analysis. The system was calibrated to ensure an appropriate phase response. In all patients, heart rate, heart rhythm, blood pressure, and oxygen saturation were continuously monitored. In addition, full 12-lead electrocardiograms were monitored during each minute of exercise and recovery. Oxyhemoglobin saturation $(\mathrm{SpO} 2)$ was continuously monitored by a finger Oscar II pulse oximeter (Datex, Helsinki, Finland).

Resting V'O2 was a 2-min average at rest and unloaded $\mathrm{V}^{\prime} \mathrm{O} 2$ was the 1-min average during the unloaded pedaling. Maximal work rate (Wmax) was defined as the highest work rate that the subject was able to maintain for at least $30 \mathrm{~s}$. The submaximal parameters of cardiopulmonary function analyzed were the peak power (peak W), oxygen uptake (peak V'O2), minute ventilation (peak VE), respiratory frequency (peak f), oxygen pulse or $\mathrm{V}^{\prime} \mathrm{O} 2 / \mathrm{HR}$ (peak O2 Pu) and peak HR. The slope of the cardiovascular response (HR slope or $\left.\Delta H R / \Delta V^{\prime} O 2\right)$ was derived by linear regression analysis of a plot of $\mathrm{HR}$ versus $\mathrm{V}^{\prime} \mathrm{O} 2$ during incremental exercise. Calculation of the oxygen debt used all VO2 during recovery above the resting VO2 until the RER was $<1.0$ for $30 \mathrm{~s}$. The work oxygen cost $\left(\Delta \mathrm{V}^{\prime} \mathrm{O} 2 / \Delta \mathrm{W}\right)$ was defined as the exercise oxygen cost (the sum of $\mathrm{V}^{\prime} \mathrm{O} 2$ during exercise above the unloaded $\mathrm{V}^{\cdot} \mathrm{O} 2$ divided by the sum of Watts during exercise) plus recovery oxygen cost (sum of $\mathrm{V}^{\prime} \mathrm{O} 2$ during recovery above rest $\mathrm{V}^{`} \mathrm{O} 2$ divided by the sum of Watts during exercise) (28).

Finally, anaerobic threshold (AT) was estimated using the nadirs of ventilator equivalents and the $\mathrm{V}$ slope method; both methods were used concurrently looking for consistency (32). If AT was clearly discernible using either of the noninvasive methods, this value was reported. When differences in AT were observed between both techniques, the average value was used. However, in situations in which AT was not discernible using either method, the AT was categorized as indeterminate. The predicted values of Jones and coworkers were used for the exercise measurements (33).

\section{Statistical analysis}

Data are presented according to current standards for the reporting of diagnostic accuracy studies (STARD) statement. Results are expressed as mean \pm standard deviation or frequency, depending on the type of data. In the univariate analysis, the Student's t test was used for comparisons between quantitative variables, and the Chi-squared and Fisher's exact tests were used for comparison of qualitative variables. For comparisons of multiple quantitative variables an analysis of variance (ANOVA) with the Bonferroni post-hoc test was used. The areas under the receiver operating characteristic (ROC) curves were calculated for quantitative variables with statistically significant results in the univariate analysis. For the statistical analysis the SPSS 15.0 package was used, considering $\mathrm{p}<0.05$ as statistically significant.

\section{Results}

Demographic and spirometric data are shown in table 2. There were no statistically significant differences between the groups in the measured variables.

Table 2.Demographic and spirometric characteristics of the study groups*

\begin{tabular}{lccc}
\hline & $\begin{array}{c}\text { SFC Group } \\
(\mathrm{N}=19)\end{array}$ & $\begin{array}{c}\text { MM Group } \\
(\mathrm{N}=27)\end{array}$ & $\begin{array}{c}\text { Control } \\
\text { Group } \\
(\mathrm{N}=18)\end{array}$ \\
$\begin{array}{l}\text { Gender, \% } \\
\text { women }\end{array}$ & 79 & 52 & 61 \\
Age, years & $43 \pm 13$ & $40 \pm 14$ & $41 \pm 6$ \\
Height, cm & $166 \pm 8$ & $164 \pm 9$ & $163 \pm 8$ \\
Weight, Kg & $65 \pm 8$ & $62 \pm 11$ & $61 \pm 8$ \\
BMI, Kg/m & $24 \pm 2.7$ & $23 \pm 3.7$ & $23 \pm 2.7$ \\
Current & 32 & 23 & 22 \\
smokers, \% & $101 \pm 15$ & $97 \pm 10$ & $100 \pm 9$ \\
FVC, \% pred. & $100 \pm 12$ & $95 \pm 7$ & $99 \pm 9$ \\
FEV, \% pred. & $84 \pm 5$ & $83 \pm 6$ & $83 \pm 5$ \\
FEV $\mathbf{1}$ /FVC, \% & & & \\
\hline
\end{tabular}

* Data presented as mean \pm standard deviation or percentage. Abbreviations: $\mathrm{BMI}=$ body mass index; $\mathrm{FVC}=$ forced vital capacity; FEV1=forced expiratory volume at 1 second.

The main parameters of respiratory, cardiovascular, and metabolic responses to exercise of the three study groups are shown in table 3 . With regard to the control subjects, patients with MM or CFS showed a limited exercise tolerance, demonstrated by their lower peak oxygen uptake and peak work rate. Between MM and CFS groups, significant differences in $\mathrm{HR}$ slope $(\mathrm{p}=0.02)$ and work $\Delta \mathrm{V}^{\prime} \mathrm{O} 2 / \Delta \mathrm{W} \quad(\mathrm{p}<0.001)$ were obtained. 
Table 3.Exercise response in the three study groups*

\begin{tabular}{|c|c|c|c|}
\hline & $\begin{array}{c}\text { SFC Group } \\
(\mathrm{n}=19)\end{array}$ & $\begin{array}{c}\text { MM Group } \\
(\mathrm{n}=27)\end{array}$ & $\begin{array}{c}\text { Control Group } \\
\qquad(\mathrm{n}=18)\end{array}$ \\
\hline Resting HR, $\min ^{-1}$ & $78 \pm 9$ & $81 \pm 16$ & $77 \pm 8$ \\
\hline Resting $\mathrm{V}^{\prime} \mathbf{O}_{2}, \mathrm{ml} / \mathrm{min}$ & $238 \pm 66$ & $240 \pm 90$ & $249 \pm 62$ \\
\hline Peak W, w & $68 \pm 34 \dagger$ & $75 \pm 32 \dagger$ & $136 \pm 36$ \\
\hline Peak VE, $1 /$ min & $41.3 \pm 15.6 \S$ & $47.6 \pm 20.3$ & $57.2 \pm 14.1$ \\
\hline BR, \% & $65 \pm 11 \dagger$ & $58 \pm 18 \dagger$ & $38 \pm 11$ \\
\hline peak $f, \min ^{-1}$ & $26 \pm 7+$ & $31 \pm 8$ & $34 \pm 4$ \\
\hline peak VT, ml & $1638 \pm 651$ & $1552 \pm 561$ & $1694 \pm 449$ \\
\hline peak $\Delta V E / \Delta V^{\prime} \mathbf{C O}_{2}$ & $31.2 \pm 5.2$ & $30.0 \pm 5.4$ & $30.2 \pm 4.9$ \\
\hline peak $\Delta V E / \Delta V^{\prime} \mathbf{O}_{2}$ & $32.3 \pm 5.7$ & $34.2 \pm 8.4$ & $32.5 \pm 8.5$ \\
\hline peak VD/VT & $0.1 \pm 0.0$ & $0.1 \pm 0.0$ & $0.2 \pm 0.0$ \\
\hline peak HR, $\min ^{-1}$ & $136 \pm 21 \dagger$ & $143 \pm 18 \dagger$ & $160 \pm 10$ \\
\hline HRR, $\min ^{-1}$ & $41 \pm 14 \dagger$ & $39 \pm 18 \dagger$ & $22.5 \pm 8.5$ \\
\hline HR slope, $1 / \mathrm{ml} / \mathrm{Kg}$ & $9.6 \pm 3.1 \dagger$ & $7.2 \pm 2.1$ & $5.8 \pm 1.2$ \\
\hline peak $\mathrm{V}^{\prime} \mathrm{O}_{2} / \mathrm{HR}, \mathrm{ml}$ & $9.9 \pm 3.9$ & $9.3 \pm 3.7$ & $11.3 \pm 2.1$ \\
\hline peak $\mathbf{V}^{\prime} \mathbf{O}_{2}, \mathrm{ml} / \mathrm{min} / \mathrm{Kg}$ & $18.5 \pm 6.6 \dagger$ & $21.1 \pm 7.9 \dagger$ & $29.9 \pm 5.6$ \\
\hline peak $\mathbf{V}^{\prime} \mathbf{O}_{2}, \%$ pred. & $70 \pm 16 \S$ & $66 \pm 21 \dagger$ & $84 \pm 8$ \\
\hline Work $\Delta \mathbf{V}^{\prime} \mathbf{O}_{2} / \Delta \mathbf{W}, \mathrm{ml} / \mathrm{min} / \mathrm{W}$ & $12.1 \pm 2.9 \mathrm{~d}$ & $16.0 \pm 3.9 \dagger$ & $11.7 \pm 1.3$ \\
\hline AT, $\% \mathrm{~V}^{\prime} \mathrm{O}_{2} \max$ & $45.4 \pm 18.6$ & $41.1 \pm 22.8 \S$ & $57.4 \pm 7.0$ \\
\hline
\end{tabular}

* Data are presented as average \pm standard deviation or percentage. Abbreviations: HR=heart rate, $\mathrm{V}^{\prime} \mathrm{O} 2=\mathrm{oxygen}$ uptake, W=work rate, $\mathrm{VE}=$ minute ventilation, $\mathrm{BR}=$ breathing reserve, $\mathrm{f}=$ respiratory rate, $\mathrm{VT}=$ tidal volume, $\mathrm{VD} / \mathrm{VT}=$ death space volume/tidal volume ratio, $\mathrm{HRR}=\mathrm{heart}$ rate reserve, $\mathrm{HR}$ slope $=$ cardiovascular response slope, $\mathrm{V}^{\prime} \mathrm{O} 2 / \mathrm{HR}=$ oxygen pulse, $\Delta \mathrm{V}^{\prime} \mathrm{O} 2 / \mathrm{W}=$ oxygen cost, $\mathrm{AT}=$ anaerobic threshold.

Average comparison by ANOVA and post-hoc Bonferroni correction: $\dagger \mathrm{p}<0.001$ vs. control group, $\ddagger \mathrm{p}<0.01$ vs. control group, $\S \mathrm{p}<0.05$ vs. control group, Il p<0.001 vs. MM group, \# p<0.01 vs. MM group.

The area under the ROC curve of the HR slope to discriminate CFS was 0.718 [CI 95\%: 0.56- 0.87] (Figure 1). The cutoff point to achieve a better sensitivity-specificity relationship was $8.651 / \mathrm{ml} / \mathrm{kg}$. In the patients with exercise intolerance, a HR slope > $8.651 / \mathrm{ml} / \mathrm{Kg}$ allowed to identify CFS with a sensitivity of 63.2 (95\%CI: $38.6-82.8 \%)$, specificity $82.1 \%$ (95\%CI: $62.4-93.2 \%$ ), positive predictive value $70.6 \%$ (95\% CI: 44.1-88.6\%), negative predictive value $76.7 \%$ (95\%CI: $57.3-89.4 \%$ ), likelihood-ratio positive 3.5 (95\%CI: $1.5-8.4)$ and accuracy $74.5 \%$ (95\%CI: $59.4-$ $85.6 \%)$.

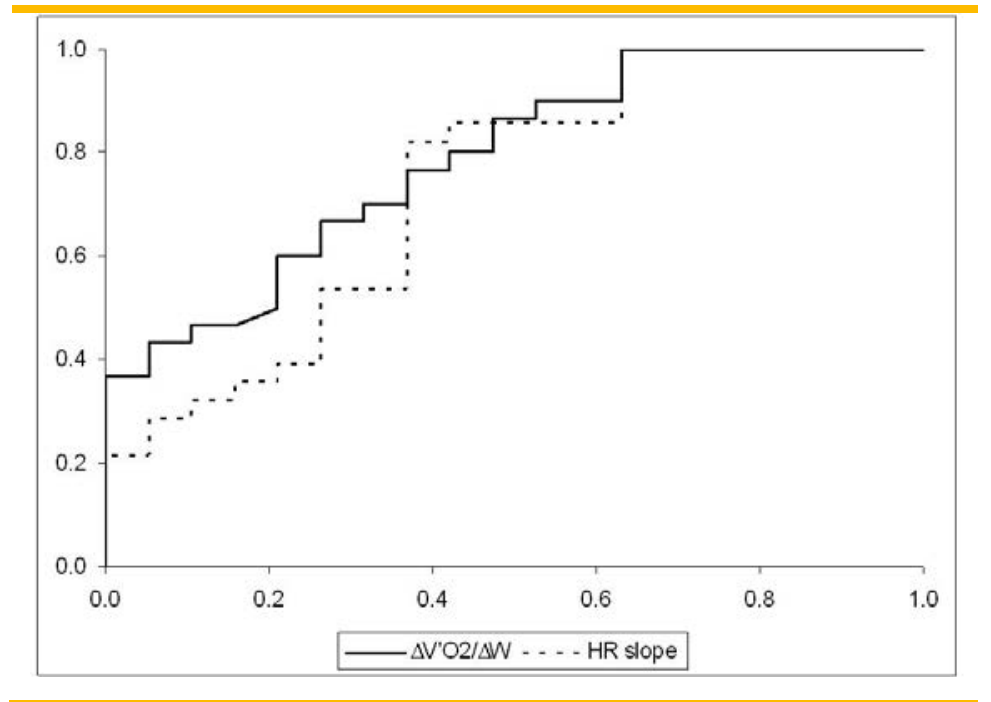

Figure 1. HR slope ROC curve to discriminate chronic fatigue syndrome (CFS) and work $\Delta \mathrm{V}^{\prime} \mathrm{O} 2 / \mathrm{W}$ ROC curve to discriminate mitochondrial myopathy (MM).

The area under the ROC curve of the work $\Delta \mathrm{V}^{\prime} \mathrm{O} 2 / \Delta \mathrm{W}$ to discriminate $\mathrm{MM}$ was 0.79 [CI $95 \%$ : 0.65-0.92] (Figure 1). A work oxygen cost $\left(\Delta \mathrm{V}^{\prime} \mathrm{O} 2 / \Delta \mathrm{W}\right)>12.8 \mathrm{ml} / \mathrm{min} / \mathrm{w}$ identify a $\mathrm{MM}$ with a sensitivity of 76.7 (95\%CI: $57.3-89.4 \%)$, specificity $57.9 \%$ (95\%CI: $34.0-78.9 \%$ ), positive predictive value

\section{x'IBJ pus}

74.2\% (95\%CI: $55.1-87.5 \%)$, negative predictive value 61.1\% (95\%CI: 36.1-81.7\%), likelihood-ratio positive 1.8 (95\%CI: $1.04-3.20)$ and accuracy $69.4 \%$ (95\%CI: $54.4-81.3 \%)$.

Figure 2 represents the probability of being a 
patient with CFS as a function of the HR slope value obtained in the cardio-pulmonary exercise test. Increases in this value produce an increase in the probability of having CFS, and patients are distributed along the entire curve starting at very low values. A cut point at $12.361 / \mathrm{ml} / \mathrm{kg}$ results in a $21 \%$ sensitivity in the ROC curve. Below this value, all patients with MM in our sample can be found.

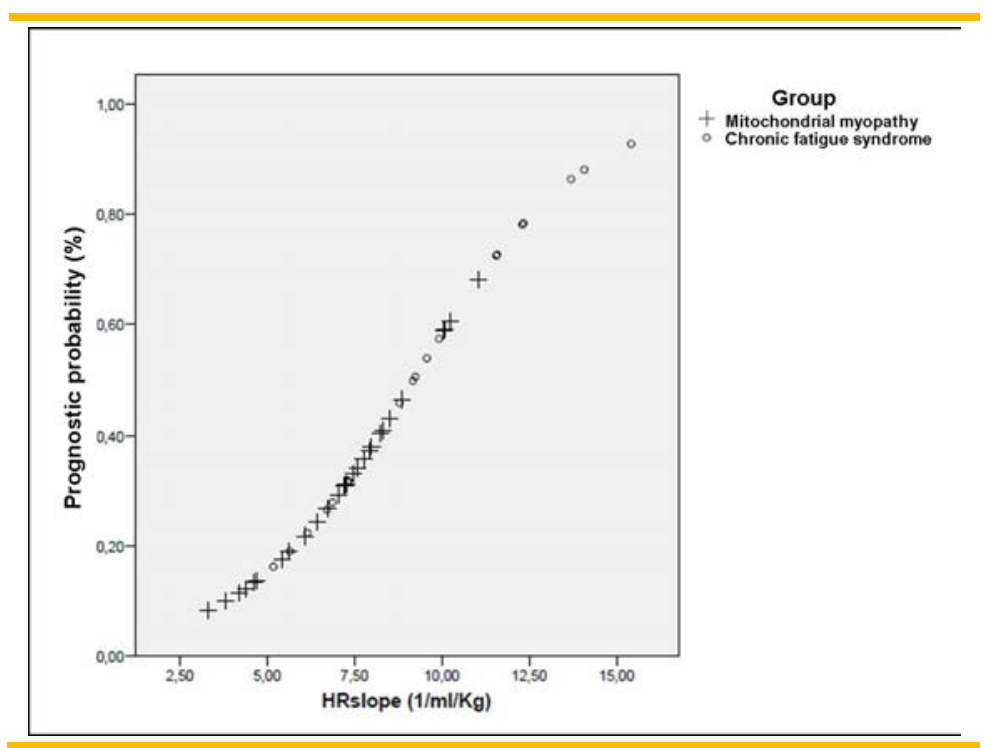

Figure 2. Probability of having mitochondrial myopathy as a function of HR slope.

Figure 3 represents the probability of being a patient with CFS as a function of the work $\Delta \mathrm{V}^{\prime} \mathrm{O} 2 / \Delta \mathrm{W}$ value obtained in the exercise tolerance test. Unlike in the previous figure, patients with CFS are not distributed along the entire curve, and have a low probability of suffering this disease with values above $17 \mathrm{ml} / \mathrm{min} /$ watt. On the other hand, values less than $10.4 \mathrm{ml} / \mathrm{min} /$ watt $(100 \%$ of sensitivity in the ROC curve) would have a low probability of belonging to the $\mathrm{MM}$ group.

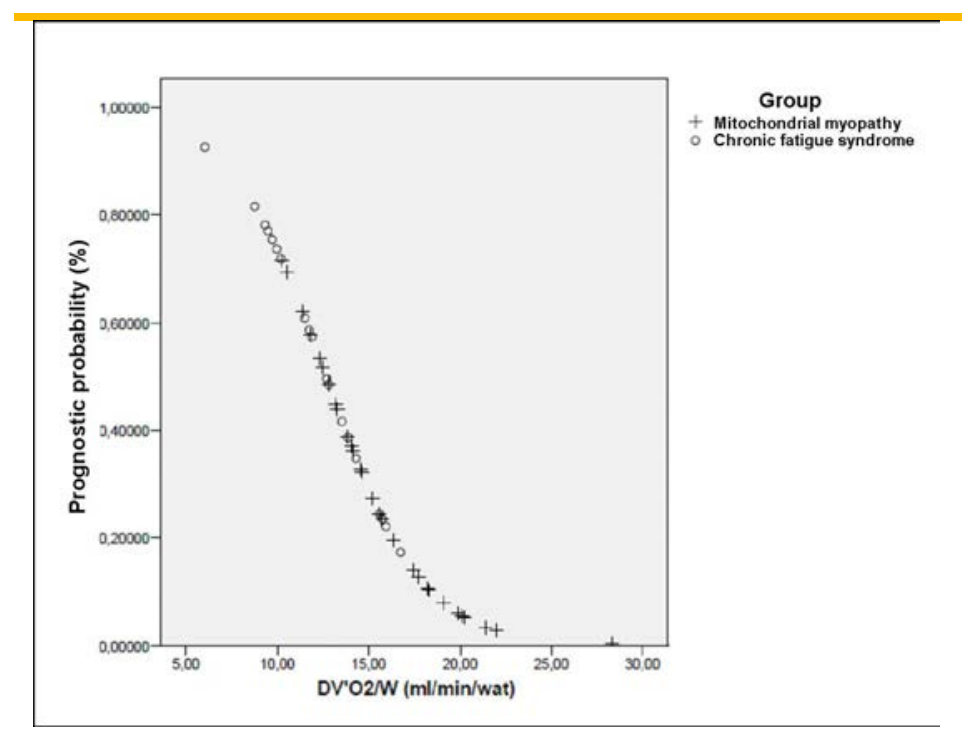

Figure 3. Probability of having mitochondrial myopathy as a function of $\Delta \mathrm{V}^{\prime} \mathrm{O} 2 / \mathrm{W}$.

\section{Discussion}

There were two major findings of this study. First, patients with $\mathrm{MM}$ and CSF presented less exercise capacity (peak $\mathrm{V}^{\prime} \mathrm{O} 2$ and peak $\mathrm{W}$ ) compared to controls. Secondly, there were important differences in the metabolic and cardiovascular response to exercise tolerance test between MM and CSF.

As reported in previous studies (4-14), peak V'O2 is diminished in both groups of patients in compared with controls. In patients with MM, oxygen consumption is limited by structural and functional 
damage in mitochondrial oxidative phosphorylation, in addition to the negative role played by lack of physical conditioning (8-14). In patients with CFS, it has been hypothesized that physical deconditioning plays a role in fatigue maintenance, since it is possible that the tendency towards hypovolemia, by reduction of venomotor tone and the depletion of salt, collaborates with the reduction in oxygen consumption to affect cardiac output (6). However, in our study, there was no significant difference between control subjects and both groups of patients in oxygen pulse (table 3 ), so the results found cannot be explained by differences in physical condition. What is the exercise limiting factor in CSF? We observed that the peak HR of the MM and CFS groups is significantly lower than that of controls, without differences in basal HR between them. The HR slope or slope with which heart rate increases is, on the other hand, significantly superior in the CFS group with respect to the two remaining comparative groups. De BP et al. (5) also reported significantly lower peak HR in CFS patients in compare with control subjects. These authors hypothesized that a lower peak HR as a consequence of a slow acceleration in response to exercise. In according to our results, this conclusion may be incorrect because of they did not measured the HR slope. We suggested that an excessive tachycardization in response to exercise provokes early fatigue and it is the exercise limiting factor in CSF.

The study of pacemaker regulation by the systemic nervous system has been the protagonist in the literature dedicated to CFS, supported by the theory that acute or persistent viral infection (post-viral CFS) favors a chronotropic hyper-response to exercise (3436). On the other hand, a disproportionate cardiac response to exercise has been documented in healthy individuals with physical deconditioning (37). In our study, with comparable degrees of physical conditioning (peak $\mathrm{V}^{\prime} \mathrm{O} 2 / \mathrm{HR}$ ) in both groups of patients, significant differences were only found in the HR slope with respect to controls in the CFS group. Therefore we can conclude that some unknown factor exists, present in CFS, that interferes with the control of heart rate, and that could favor the maintenance of fatigue. Along these lines Boneva et al (38) find that compared to controls, patients with CFS present an increased HR and a reduction in the variability of HR that persists during sleep, which is associated with a higher basal level of norepinephrine and a lower basal level of aldosterone. These findings support the theory that alterations in cardiovascular regulation, secondary to an autonomic cardiovascular deregulation in favor of the sympathetic system, play an important role in the physiopathology of this disease.

What is most relevant for clinical practice, and the objective of our study, is to find non-invasive and easily reproducible parameters that permit the differentiation of patients with CFS and MM, since patients with CFS may simulate the presentation of latent MM. In our study, HR slope and work oxygen cost $\left(\Delta \mathrm{V}^{\prime} \mathrm{O} 2 / \Delta \mathrm{W}\right)$ have shown significant discriminative capacity between CFS and MM patients.

The probability curve of having CFS as a function of the HR slope (Figure 2) reflects how an increase in HR slope, that is "greater tachycardization" in response to exercise, increases the probability of belonging to the group with CFS. In our series no patient with MM was found above $10.61 / \mathrm{ml} / \mathrm{kg}$. For this value, according to the model we have developed, the probability of a patient belonging to the CFS group is approximately $75 \%$. The area under the ROC curve of this parameter is $0.731 \quad(\mathrm{p}<0.02)$. This value is acceptable, even more so taking into account the sample size of our study.

To our knowledge, any previous study has accounted for the increase in recovery oxygen uptake in the evaluation of efficiency of patients with exercise limitation secondary to MM or CFS. We found total oxygen cost is greater when oxygen consumption during recovery is included for patients with mitochondrial myopathy. This finding implies that MM patients were not efficient but rather were accumulating a large oxygen debt due to reliance on anaerobic metabolism that was repaid after the completion of exercise. The probability curve for having CFS as a function of the work oxygen cost adopts a more sigmoid shape than that described before, and is correlated with a significantly greater area under the ROC curve (0.787). In figure 3 we can see how values less than $10.4 \mathrm{ml} / \mathrm{min} /$ watt are not found in any patient with MM in our sample. With this value, the probability of belonging to the CFS group is $73 \%$. In the reverse sense, a greater work $\Delta \mathrm{V}^{\prime} \mathrm{O} 2 / \Delta \mathrm{W}$ means less probability of having CFS, so that for values greater than $16 \mathrm{ml} / \mathrm{min} /$ watt all patients in our study belong to the MM group.

In conclusion, the slope of the cardiovascular response (HR slope) and the work oxygen cost $\left(\Delta \mathrm{V}^{\prime} \mathrm{O} 2 / \Delta \mathrm{W}\right)$ have shown to be useful in discriminating between chronic fatigue syndrome and mitochondrial myopathy. More powerful studies should be conducted to support the value of the cardiopulmonary exercise testing as a non-invasive tool in the study of patients with idiopathic chronic fatigue.

\section{REFERENCES}

[1] Fukuda K, Straus SE, Hickie I, Sharpe MC, Dobbins JG, Komaroff A. The chronic fatigue syndrome: a comprehensive approach to its definition and study. International Chronic Fatigue Syndrome Study Group. Ann Intern Med. 1994 Dec 15;121(12):953-9.

[2] Chinnery PF, Johnson MA, Wardell TM, Singh-Kler R, Hayes C, Brown DT, Taylor RW, Bindoff LA, Turnbull DM. The epidemiology of pathogenic mitochondrial DNA mutations. Ann Neurol. 2000 Aug;48(2):188-93.

[3] Mitochondrial Medicine Society's Committee on 
Diagnosis, Haas RH, Parikh S, Falk MJ, Saneto RP, Wolf NI, Darin N, Wong LJ, Cohen BH, Naviaux RK. The in-depth evaluation of suspected mitochondrial disease. Mol Genet Metab. 2008 May;94(1):16-37.

[4] Jammes Y, Steinberg JG, Mambrini O, Brégeon F, Delliaux S. Chronic fatigue syndrome: assessment of increased oxidative stress and altered muscle excitability in response to incremental exercise. J Intern Med. 2005 Mar;257(3):299-310.

[5] De Becker P, Roeykens J, Reynders M, McGregor N, De Meirleir K. Exercise capacity in chronic fatigue syndrome. Arch Intern Med. 2000 Nov 27;160(21):3270-7. Erratum in: Arch Intern Med 2001 Sep 10;161(16):2051-2.

[6] Farquhar WB, Hunt BE, Taylor JA, Darling SE, Freeman R. Blood volume and its relation to peak $\mathrm{O}(2)$ consumption and physical activity in patients with chronic fatigue. Am J Physiol Heart Circ Physiol. 2002 Jan;282(1):H66-71.

[7] Wallman KE, Morton AR, Goodman C, Grove R. Physiological responses during a submaximal cycle test in chronic fatigue syndrome. Med Sci Sports Exerc. 2004 Oct;36(10):1682-8.

[8] Taivassalo T, Jensen TD, Kennaway N, DiMauro S, Vissing J, Haller RG. The spectrum of exercise tolerance in mitochondrial myopathies: a study of 40 patients. Brain. $2003 \mathrm{Feb}$;126(Pt 2):413-23.

[9] Bogaard JM, Busch HF, Arts WF, Heijsteeg M, Stam H, Versprille A. Metabolic and ventilatory responses to exercise in patients with a deficient $\mathrm{O} 2$ utilization by a mitochondrial myopathy. Adv Exp Med Biol. 1985;191:409-17.

[10] Dandurand RJ, Matthews PM, Arnold DL, Eidelman DH. Mitochondrial disease. Pulmonary function, exercise performance, and blood lactate levels. Chest. $1995 \mathrm{Jul} ; 108(1): 182-9$.

[11] Fernández J, Montemayor T, Bautista J, Márquez R, Jiménez L, Arenas J, Campos Y, Castillo J. [The use of cardiopulmonary exercise test in patients with mitochondrial myopathies]. Med Clin (Barc). 2000 Feb 5;114(4):121-7.

[12] Hooper RG, Thomas AR, Kearl RA. Mitochondrial enzyme deficiency causing exercise limitation in normal-appearing adults. Chest. 1995 Feb;107(2):31722.

[13] Jeppesen TD, Olsen D, Vissing J. Cycle ergometry is not a sensitive diagnostic test for mitochondrial myopathy. J Neurol. 2003 Mar;250(3):293-9.

[14] Finsterer J. The usefulness of lactate stress testing in the diagnosis of mitochondrial myopathy. Concerning the paper "cycle ergometry is not a sensitive diagnostic test for mitochondrial myopathy" by Jeppesen et al. J Neurol. 2005 Jul;252(7):857-8.

[15] Kent-Braun JA, Sharma KR, Weiner MW, Massie B, Miller RG. Central basis of muscle fatigue in chronic fatigue syndrome. Neurology. 1993 Jan;43(1):125-31.

[16] LaManca JJ, Peckerman A, Walker J, Kesil W, Cook S, Taylor A, Natelson BH. Cardiovascular response during head-up tilt in chronic fatigue syndrome. Clin Physiol. 1999 Mar;19(2):111-20.

[17] Montague TJ, Marrie TJ, Klassen GA, Bewick DJ, Horacek BM. Cardiac function at rest and with exercise

\section{Plus}

in the chronic fatigue syndrome. Chest. 1989 Apr;95(4):779-84.

[18] Riley MS, O'Brien CJ, McCluskey DR, Bell NP, Nicholls DP. Aerobic work capacity in patients with chronic fatigue syndrome. BMJ. 1990 Oct 27;301(6758):953-6.

[19] Sisto SA, LaManca J, Cordero DL, Bergen MT, Ellis SP, Drastal S, Boda WL, Tapp WN, Natelson BH. Metabolic and cardiovascular effects of a progressive exercise test in patients with chronic fatigue syndrome. Am J Med. 1996 Jun;100(6):634-40.

[20] Gibson H, Carroll N, Clague JE, Edwards RH. Exercise performance and fatiguability in patients with chronic fatigue syndrome. J Neurol Neurosurg Psychiatry. 1993 Sep;56(9):993-8.

[21] Stokes MJ, Cooper RG, Edwards RH. Normal muscle strength and fatigability in patients with effort syndromes. BMJ. 1988 Oct 22;297(6655):1014-7.

[22] Montague TJ, Marrie TJ, Bewick DJ, Spencer CA, Kornreich F, Horacek BM. Cardiac effects of common viral illnesses. Chest. 1988 Nov;94(5):919-25.

[23] Wyller VB, Saul JP, Walløe L, Thaulow E. Sympathetic cardiovascular control during orthostatic stress and isometric exercise in adolescent chronic fatigue syndrome. Eur J Appl Physiol. 2008 Apr;102(6):62332.

[24] Bou-Holaigah I, Rowe PC, Kan J, Calkins H. The relationship between neurally mediated hypotension and the chronic fatigue syndrome. JAMA. 1995 Sep 27;274(12):961-7.

[25] Peckerman A, LaManca JJ, Dahl KA, Chemitiganti R, Qureishi B, Natelson BH. Abnormal impedance cardiography predicts symptom severity in chronic fatigue syndrome. Am J Med Sci. 2003 Aug;326(2):5560.

[26] Dandurand RJ, Matthews PM, Arnold DL, Eidelman DH. Mitochondrial disease. Pulmonary function, exercise performance, and blood lactate levels. Chest. $1995 \mathrm{Jul} ; 108(1): 182-9$.

[27] Flaherty KR, Wald J, Weisman IM, Zeballos J, Schork MA, Blaivas M, Rubenfire M, Martinez FJ. Unexplained exertional limitation. Characterization of patients with mitochondrial myopathy. Am J Respir Crit Care Med 2001; 184: 426-432.

[28] Walker UA, Collins S, Byrne E. Respiratory chain encephalomyopathies: a diagnostic classification. Eur Neurol. 1996;36(5):260-7.

[29] Miller MR, Hankinson J, Brusasco V, Bugos F, Casaburi R, Coates A, Crapo R, Enright P, van der Grinten CP, Gustafsson P, Jensen R, Johnson DC, MacIntyre N, McKay R, Navajas D, Pedersen OF, Pellegrino R, Viegi G, Wanger J; ATS/ERS Task Force. Standardization of spirometry. Eur Respir J 2005;26:319-338. 